\title{
EFEKTIFITAS MATH THINKERS PADA MATERI GEOMETRI BANGUN DATAR SEGIEMPAT DAN SEGITIGA
}

\author{
Zharotul Azizah \\ Universitas Muhammadiyah Surabaya \\ zharotula@gmail.com
}

\begin{abstract}
ABSTRAK
Penelitian ini bertujuan untuk mengetahui efektivitas pembelajaran matematika melalui Media Math Thinkers pada siswa kelas VII-B di SMP Muhammadiyah 13 Surabaya. Subjek penelitian ini adalah siswa kelas VII-B SMP Muhammadiyah 13 Surabaya yang berjumlah 21 siswa. Jenis penelitian ini menggunakan penelitian deskriptif kuantitatif. Instrumen dalam penelitian ini adalah tes tulis, lembar observasi aktivitas siswa, lembar observasi kemampuan guru dalam mengelola proses pembelajaran, dan angket respon siswa. Hasil penelitian menunjukkan bahwa: (1) Efektivitas kegiatan siswa dicapai karena tujuh dari delapan kegiatan siswa dalam rentang waktu yang ideal; (2) Efektivitas kemampuan guru dalam mengelola proses pembelajaran tercapai dengan baik; (3) Kelengkapan hasil belajar siswa menunjukkan bahwa 70\% dari semua siswa telah mencapai KKM atau kelengkapan secara individu; dan (4) Respon siswa terhadap pembelajaran menunjukkan respon positif. Dengan demikian, pendekatan Media Math Thinkers efektif digunakan dalam proses pembelajaran matematika di kelas VII-B di SMP Muhammadiyah 13 Surabaya.
\end{abstract}

Kata kunci: efektivitas, media math thinkers.

\begin{abstract}
This research aims to determine the effectiveness of learning mathematics through Math Thinkers media on students of class VII-B in SMP Muhammadiyah 13 Surabaya. The subjects of this research are students of class VII-B SMP Muhammadiyah 13 Surabaya, amounting to 21 students. The type of this research used descriptive quantitative research. The instruments in this research are writing test, students' activity observation sheet, teacher ability observation sheet in managing learning process, and students' response questionnaire. The results showed that: (1) The effectiveness of students' activity was achieved because seven of the eight activities of students in the ideal time range; (2) The effectiveness of teacher ability in managing learning process is well achieved; (3) Completeness of students' learning result showed $70 \%$ of all students have reached KKM or completeness individually; and (4) Students' response to learning showed a positive response. Thus, the approach of Math Thinkers Media was effectively used in mathematics learning process in grade VII-B at SMP Muhammadiyah 13 Surabaya.
\end{abstract}

Keywords: effectiveness, math thinkers media.

\section{PENDAHULUAN}

Alasan geometri penting untuk dipelajari diantaranya adalah: (a) Geometri mampu memberikan pengetahuan yang lebih lengkap mengenai dunia; (b) Eksplorasi geometri dapat mengembangkan kemampuan pemecahan masalah; (c) 
Geometri memainkan peranan penting dalam mempelajari konsep lain dalam pembelajaran matematika; (d) Geometri digunakan setiap hari oleh banyak orang; (e) Geometri adalah pelajaran yang menyenangkan (Van de Walle, 2001).

Namun, prestasi belajar geometri siswa SD dan SMP di Indonesia masih tergolong rendah. Dalam TIMSS (2011) ditemukan bahwa prestasi belajar geometri siswa kelas VIII di Indonesia memperoleh urutan ke-37 dari 40 negara partisipan lainnya (Nopriana, 2017). Selain itu, prestasi belajar geometri siswa kelas VIII mengalami penurunan dari tahun 2007. Dibandingkan Negara berkembang lainnya, Indonesia merupakan salah satu negara yang memiliki perkembangan prestasi belajar matematika khususnya geometri tergolong rendah.

Penggunaan media merupakan salah satu cara yang efektif dalam menambah kebermaknaan proses pembelajaran. Tujuan utama penggunaan media ialah agar pesan atau informasi yang dikomunikasikan tersebut dapat diserap semaksimal mungkin oleh para siswa sebagai penerima informasi (Soeparno, 1988). Selain itu, media juga dapat menjadikan proses belajar di kelas menjadi menyenangkan dan tidak membosankan.

Math Thinkers merupakan media yang modelnya terinspirasi dari mainan edukasi untuk anak bernama Fun Thinkers. Tidak banyak orang tua yang mengetahui mainan edukasi ini, dikarenakan harganya yang cukup mahal. Namun peneliti akan membuat media Math Thinkers dengan harga yang terjangkau dan bahan-bahan yang mudah didapat. Math Thinkers bukanlah peraga yang diperagakan didepan kelas, Math Thinkers adalah media yang bersifat gaming atau permainan. Tujuan dari Math Thinkers sendiri adalah agar siswa tidak merasa bosan dengan belajar yang monoton dan hanya mendengarkan.

Dari penjelasan diatas, maka peneliti ingin menggunakan Math Thinkers sebagai media pada pembelajaran geometri. Karena selama ini pembelajaran geometri menggunakan media-media tradisional yang tidak menarik. Peneliti ingin melakukan penelitian mengenai "Efektifitas Math Thinkers pada Materi Geometri Bangun Datar”. 


\section{METODE PENELITIAN}

Jenis penelitian yang digunakan adalah penelitian deskriptif kuantitatif. Karena peneltiian ini menganalisa keefektifan pembelajaran matematika dengan media Math Thinkers pada siswa kelas VII-B SMP Muhamamdiyah 13 Surabaya. Kemudian mendeksripsikan hasil data dari tes hasil belajar siswa, aktifitas siswa, kemampuan guru dalam mengelola pembelajaran, dan respon siswa. instrumen yang digunakan dalam penelitian ini adalah lembar observasi kemampuan guru dalam mengelola pembelajaran, lembar observasi aktifitas siswa, soal tes hasil belajar, dan angket respon siswa. dalam penelitian ini teknik analisis data yang digunakan adalah analisis deskriptif. Tujuan dari analisis deskriptif adalah menganalisis data hasil pengamatan dengan cara mendeskripsikan dan menjawab pertanyaan penelitian. Pada penelitian deskriptif statistika yang digunakan adalah statistika deskriptif seperti teknik presentase, perhitungan rata-rata, dan lain-lain.

Data yang dianalisis secara deskriptif dalam penelitian ini adalah ketuntasan hasil belajar siswa, aktifitas siswa, kemampuan guru dalam mengelola pembelajara, serta respon siswa terhadap media Math Thinkers.

1. Analisis data ketuntasan hasil belajar

Untuk memperoleh data tentang ketuntasan hasil belajar siswayaitu dengan melihat hasil (skor) pengetahuan tes mereka. Berdasarkan kurikulum K13 yang diberlakukan di SMP Muhammadiyah 13 Surabaya, siswa dikatakan tuntas secara individual bila nilai kompetensi pengetahuannya mendapatkan nilai KKM $\geq 75$ atau dengan predikat baik. Dan ketuntasan secara klasikal dicapai jika terdapat $\geq$ $70 \%$ telah tuntas pada kelas tersebut.

Ketuntasan hasil belajar individual tercapai apabila:

Nilai $=\frac{\text { nilai yang diperoleh }}{\text { jumlah nilai maksimal }} \times 100$

(Ariani, 2014)

Presentase ketercapaian hasil belajar klasikal tercapai apabila:

Presentase ketercapaian $=\frac{\text { banyak siswa yang tuntas }}{\text { skor maksimum banyak siswa seluruhnya }} \times 100 \%$

(Ariani, 2014)

2. Analisis data aktifitas siswa

Pembelajaran matematika dengan peraga Math Thinkers dikatakan efektif apabila enam dari tujuh indikator aktivitas siswa telah mencapai waktu ideal dari 
kategori aktivitas siswa yang sudah ditetapkan dalam penyusunan Rencana Pelaksanaan Pembelajaran (RPP) dengan toleransi 5 menit. Alokasi waktu untuk satu kali pertemuan 80 menit. Adapun criteria aktivitas siswa dapat dilihat pada Tabel 1.

Tabel 1. Kriteria Aktivitas Siswa yang Diamati

\begin{tabular}{|c|c|c|c|}
\hline No. & Kategori Aktivitas Siswa yang Diamati & $\begin{array}{l}\text { Waktu } \\
\text { Ideal } \\
\text { (menit) }\end{array}$ & $\begin{array}{c}\text { Rentang } \\
\text { Waktu dengan } \\
\text { Toleransi } 5 \\
\text { Menit (menit) }\end{array}$ \\
\hline 1 & Mendengarkan dan mengamati & 15 & $10 \leq x \leq 20$ \\
\hline 2 & Melakukan tanya jawab dengan guru & 10 & $5 \leq x \leq 15$ \\
\hline 3 & $\begin{array}{l}\text { Membaca dan memahami materi dengan mencari } \\
\text { informasi dari buku atau sumber lain }\end{array}$ & 10 & $5 \leq x \leq 15$ \\
\hline 4 & $\begin{array}{l}\text { Berdiskusi dengan kelompok serta berpartisipasi } \\
\text { aktif dalam kegiatan }\end{array}$ & 30 & $25 \leq x \leq 35$ \\
\hline 5 & Mempresentasikan hasil kelompok & 10 & $5 \leq x \leq 15$ \\
\hline 6 & $\begin{array}{l}\text { Menanggapi atau mengajukan pertanyaan saat } \\
\text { presentasi kelompok }\end{array}$ & 5 & $0 \leq \mathrm{x} \leq 10$ \\
\hline 7 & $\begin{array}{c}\text { Perilaku yang tidak relevan dengan KBM } \\
\text { Total Waktu }\end{array}$ & $\begin{array}{c}0 \\
80\end{array}$ & $\begin{array}{l}0 \leq x \leq 5 \\
\text { Efektif }\end{array}$ \\
\hline
\end{tabular}

3. Kemampuan guru dalam mengelola pembelajaran

Data hasil pengamatan kemampuan guru dalam mengelola pembelajaran dengan peraga Math Thinkers dicari rata-ratanya setiap aspek dari 2 pertemuan yaitu pertemuan 1 dan 2. Pembelajaran matematika dikatakan efektif jika mencapai kriteria baik. Adapun kriteria kemampuan guru dalam mengelola pembelajaran dapat dilihat pada Tabel 2.

Skor dari tiap aspek yang diamati selama beberapa kali pertemuan diratarata dengan cara:

Skor $=\frac{\text { jumlah skor yang diperoleh guru }}{\text { banyaknya pertemuan }}$

(Amala, 2016)

Tabel 2. Interpretasi Kemampuan Guru dalam Mengelola Pembelajaran

\begin{tabular}{cc}
\hline Nilai & Kriteria \\
\hline $0,0 \leq K G<1,0$ & Tidak baik \\
$1,0 \leq K G<2,0$ & Kurang baik \\
$2,0 \leq K G<3,0$ & Baik \\
$3,0 \leq K G<4,0$ & Sangat Baik \\
\hline
\end{tabular}


4. Respon siswa

Data respon siswa dianalisis dengan menggunakan persentase. Respon siswa dikatakan efektif jika persentase respon siswa yang menjawab "setuju/tidak setuju" untuk jawaban positif adalah sebesar 70\% atau lebih. Persentase setiap respon siswa dianalisis dengan rumus:

$\mathrm{P}=\frac{A}{B} \times 100 \%$

dengan:

$P$ : Persentase respon siswa

$A$ : Banyak siswa yang memilih

$B$ : Jumlah siswa (responden)

Selanjutnya Persentase tersebut dikonversikan dengan kategori sebagai berikut:

Tabel 3. Interpretasi Respon siswa terhadap Pembelajaran

\begin{tabular}{cc}
\hline Persentase Respon Siswa & Kriteria \\
\hline $0 \% \leq \mathrm{R}<20 \%$ & Tidak Positif \\
$20 \% \leq \mathrm{R}<40 \%$ & Kurang Positif \\
$40 \% \leq \mathrm{R}<60 \%$ & Cukup Positif \\
$60 \% \leq \mathrm{R}<80 \%$ & Positif \\
$80 \% \leq \mathrm{R}<100 \%$ & Sangat Positif \\
\hline
\end{tabular}

\section{HASIL PENELITIAN DAN PEMBAHASAN}

Dalam penelitian ini, peneliti membagi analisis data menjadi dua sub kompetensi dasar yaitu: 1) menyebutkan sifat-sifat bangun datar segiempat dan segitiga, 2) menghitung luas dan keliling bangun datar segiempat dan segitiga.

1. Ketuntasan Hasil Belajar Siswa

Rekapitulasi ketuntasan hasil belajar siswa pada sub kompetensi dasar 1 dapat dilihat pada Tabel 4.

Tabel 4. Rekapitulasai Ketuntasan Hasil Belajar Siswa pada Sub Kompetensi Dasar 1

\begin{tabular}{cccc}
\hline & $\boldsymbol{\Sigma}$ siswa & Presentase & Rata-rata \\
\hline Tuntas (nilai $\geq 75)$ & 15 & $71.43 \%$ & \\
Tidak tuntas (nilai $<75)$ & 6 & $28.57 \%$ & 76.67 \\
Jumlah & $\mathbf{2 1}$ & $\mathbf{1 0 0 \%}$ & \\
\hline
\end{tabular}


Berdasarkan rekapitulasi ketuntasan belajar, diperoleh secara klasikal ada $71.43 \% \approx 71 \%$ siswa yang tuntas. Dengan demikian ketuntasan hasil belajar tercapai karena siswa yang tuntas hasil belajarnya $\geq 70 \%$.

Rekapitulasi ketuntasan hasil belajar siswa pada sub kompetensi dasar 2 dapat dilihat pada Tabel 5.

Tabel 5. Rekapitulasai ketuntasan hasil belajar siswa pada sub kompetensi dasar 2

\begin{tabular}{cccc}
\hline & $\boldsymbol{\Sigma}$ siswa & Presentase & Rata-rata \\
\hline Tuntas (nilai $\geq 75$ ) & 15 & $71.43 \%$ & \\
Tidak tuntas (nilai $<75$ ) & 6 & $28.57 \%$ & 75.09 \\
Jumlah & $\mathbf{2 1}$ & $\mathbf{1 0 0 \%}$ & \\
\hline
\end{tabular}

Berdasarkan rekapitulasi ketuntasan hasil belajar di atas, diperoleh secara klasikal ada $71.43 \% \approx 71 \%$ siswa yang tuntas. Dengan demikian ketuntasan hasil belajar siswa secara klasikal tercapai karena jumlah siswa yang tuntas hasil belajarnya $\geq 70 \%$ dari jumlah siswa.

\section{Aktifitas Siswa}

Menurut kriteria rentang waktu ideal aktifitas siswa selama pembelajaran sub kompetensi dasar 1 dengan media Math Thinkers, maka kesimpulan efektifitas tiap sub aktifitas siswa dapat dilihat pada Tabel 6.

Tabel 6. Kesimpulan efektifitas waktu aktifitas siswa selama pembelajaran pada sub KD-1

\begin{tabular}{clccc}
\hline No. & \multicolumn{2}{c}{ Kategori Aktivitas Siswa yang Diamati } & $\begin{array}{c}\text { Waktu } \\
\text { (menit) }\end{array}$ & Keterangan \\
\hline 1 & $\begin{array}{l}\text { Mendengarkan dan mengamati guru } \\
\text { menjelaskan }\end{array}$ & saat & 20 & Efektif \\
2 & $\begin{array}{l}\text { Melakukan tanya jawab dengan guru } \\
\text { Membaca dan memahami materi dengan mencari }\end{array}$ & 10 & Efektif \\
& $\begin{array}{l}\text { informasi dari buku atau sumber lain } \\
\text { Berdiskusi dengan kelompok serta berpartisipasi } \\
\text { aktif dalam kegiatan }\end{array}$ & 31 & Efektif \\
5 & $\begin{array}{l}\text { Mempresentasikan hasil kelompok } \\
\text { Menanggapi atau mengajukan pertanyaan saat } \\
\text { presentasi kelompok }\end{array}$ & 10 & Efektif \\
$\begin{array}{l}\text { Perilaku yang tidak relevan dengan KBM } \\
\text { Kesimpulan }\end{array}$ & 5 & Efektif \\
\hline
\end{tabular}


Berdasarkan hasil pengamatan yang terdapat dalam Tabel 6 data aktivitas siswa selama pembelajaran dengan menggunakan media Math Thinkers pada sub KD-1 dengan 8 indikator aktivitas siswa dalam kriteria efektif.

Selanjutnya hasil aktivitas siswa selama berlangsungnya pembelajaran dengan media Math Thinkers pada sub KD-2 diperoleh data seperti yang disajikan pada Tabel 7.

Tabel 7. Waktu Ideal Aktifitas Siswa Selama Pembelajaran pada Sub KD-2

\begin{tabular}{|c|c|c|c|}
\hline No. & Kategori Aktivitas Siswa yang Diamati & $\begin{array}{l}\text { Waktu } \\
\text { Ideal } \\
\text { (menit) }\end{array}$ & Keterangan \\
\hline 1 & Mendengarkan dan mengamati & 20 & Efektif \\
\hline 2 & Melakukan tanya jawab dengan guru & 8 & Efektif \\
\hline 3 & $\begin{array}{l}\text { Membaca dan memahami materi dengan mencari } \\
\text { informasi dari buku atau sumber lain }\end{array}$ & 14 & Efektif \\
\hline 4 & $\begin{array}{l}\text { Berdiskusi dengan kelompok serta berpartisipasi } \\
\text { aktif dalam kegiatan }\end{array}$ & 33 & Efektif \\
\hline 5 & Mempresentasikan hasil kelompok & 10 & Efektif \\
\hline 6 & $\begin{array}{l}\text { Menanggapi atau mengajukan pertanyaan saat } \\
\text { presentasi kelompok }\end{array}$ & 8 & Efektif \\
\hline 7 & $\begin{array}{c}\text { Perilaku yang tidak relevan dengan KBM } \\
\text { Kesimpulan }\end{array}$ & 6 & $\begin{array}{l}\text { Tidak Efektif } \\
\text { Efektif }\end{array}$ \\
\hline
\end{tabular}

Berdasarkan hasil pengamatan yang terdapat dalam Tabel 7 data aktivitas siswa selama pembelajaran dengan menggunakan media Math Thinkers pada sub KD-2 dengan 7 indikator aktivitas siswa dalam kriteria efektif.

3. Kemampuan Guru Mengelola Pembelajaran

Menurut kriteria kemampuan guru dalam mengelola pembelajaran sub KD-1, diperoleh data seperti yang disajikan pada tabel 8 dibawah ini:

Tabel 8. Data Pengamatan Kemampuan Guru Dalam Mengelola Pembelajaran Dengan Media Math Thikers Pada Sub KD-1

\begin{tabular}{lcc}
\hline \multicolumn{1}{c}{ Aspek yang diamati } & $\begin{array}{c}\text { Rata-Rata Nilai } \\
\text { Pertemuan ke-1 }\end{array}$ & Kriteria \\
\hline Pendahuluan & 3.4 & Sangat Baik \\
Kegiatan Inti & 3.4 & Sangat Baik \\
Penutup & 3 & Sangat Baik \\
Pengelolaan waktu & 3 & Sangat Baik \\
Suasana Kelas & 3 & Sangat Baik \\
Rata-rata aspek yang diamati & $\mathbf{3 . 1 6}$ & Sangat Baik (Efektif) \\
\hline
\end{tabular}


Berdasarkan hasil pengamatan yang terdapat dalam tabel 8 data kemampuan guru selama pembelajaran dengan menggunakan media Math Thinkers pada sub KD-1 dalam kriteria efektif.

Selanjutnya hasil kemampuam guru dalam mengelola pembelajaran selama berlangsungnya pembelajaran media Math Thinkers pada sub kompetensi dasar 2. Menurut kriteria kemampuan guru dalam mengelola pembelajaran yang telah ditetapkan, diperoleh data seperti yang disajikan pada Tabel 9.

Tabel 9. Data Pengamatan Kemampuan guru dalam mengelola pembelajaran dengan media Math Thikers pada sub KD-2

\begin{tabular}{lcc}
\hline \multicolumn{1}{c}{ Aspek yang diamati } & $\begin{array}{c}\text { Rata-Rata Nilai } \\
\text { Pertemuan ke-2 }\end{array}$ & Kriteria \\
\hline Pendahuluan & 3.2 & Sangat baik \\
Kegiatan Inti & 3.3 & Sangat baik \\
Penutup & 3 & Sangat baik \\
Pengelolaan waktu & 3 & Sangat baik \\
Suasana Kelas & 3 & Sangat baik \\
Rata-rata aspek yang diamati & $\mathbf{3 , 1}$ & Sangat baik (Efektif) \\
\hline
\end{tabular}

Berdasarkan hasil pengamatan yang terdapat dalam tabel 9 data kemampuan guru selama pembelajaran dengan menggunakan media Math Thinkers pada sub KD-2 dalam kriteria efektif.

\section{Respon Siswa}

Hasil data angket respon siswa dapat dilihat pada tabel 10 dibawah ini:

Tabel 10. Hasil Angket Respon Siswa

\begin{tabular}{|c|c|c|c|}
\hline \multirow{2}{*}{ No. } & \multirow{2}{*}{ Uraian } & \multicolumn{2}{|c|}{ Jumlah dan presentase } \\
\hline & & Ya & Tidak \\
\hline 1. & Apakah media Math Thinkers menarik? & $\begin{array}{c}21 \\
(100 \%)\end{array}$ & $\begin{array}{c}0 \\
(0 \%)\end{array}$ \\
\hline 2. & $\begin{array}{l}\text { Apakah kesanmu menyenangkan selama } \\
\text { mengikuti pelajaran dengan media Math Thinker? }\end{array}$ & $\begin{array}{c}21 \\
(100 \%)\end{array}$ & $\begin{array}{c}0 \\
(0 \%)\end{array}$ \\
\hline 3. & $\begin{array}{l}\text { Apakah media Math Thinkers membantu anda } \\
\text { lebih memahami materi yang disampaikan? }\end{array}$ & $\begin{array}{c}21 \\
(100 \%)\end{array}$ & $\begin{array}{c}0 \\
(0 \%)\end{array}$ \\
\hline 4. & $\begin{array}{l}\text { Apakah media Math Thinkers membuat materi } \\
\text { yang disampaikan lebih runtut? }\end{array}$ & $\begin{array}{c}18 \\
(85,71 \%)\end{array}$ & $\begin{array}{c}3 \\
(14,29 \%)\end{array}$ \\
\hline 5. & $\begin{array}{l}\text { Apakah kamu berharap media Math Thinkers } \\
\text { digunakan pada pokok bahasan lain? }\end{array}$ & $\begin{array}{c}17 \\
(80,95 \%)\end{array}$ & $\begin{array}{c}4 \\
(19,05 \%)\end{array}$ \\
\hline 6. & $\begin{array}{l}\text { Apakah media Math Thinkers membuat pokok } \\
\text { bahasan bangun datar terasa lebih nyata? }\end{array}$ & $\begin{array}{c}20 \\
(95,24 \%)\end{array}$ & $\begin{array}{c}1 \\
(4,76 \%)\end{array}$ \\
\hline 7. & $\begin{array}{l}\text { Apakah media Math Thinkers dapat kamu } \\
\text { gunakan dimana saja? }\end{array}$ & $\begin{array}{c}15 \\
(71,43 \%)\end{array}$ & $\begin{array}{c}6 \\
(28,57 \%)\end{array}$ \\
\hline 8. & $\begin{array}{l}\text { Apakah media Math Thinkers membuat kamu } \\
\text { lebih aktif belajar? }\end{array}$ & $\begin{array}{c}16 \\
(76,19 \%)\end{array}$ & $\begin{array}{c}5 \\
(13,81 \%)\end{array}$ \\
\hline 9. & Apakah kamu senang jika gurumu mengajar & 20 & 1 \\
\hline
\end{tabular}




\begin{tabular}{|c|c|c|c|}
\hline \multirow{2}{*}{ No. } & \multirow{2}{*}{ Uraian } & \multicolumn{2}{|c|}{ Jumlah dan presentase } \\
\hline & & Ya & Tidak \\
\hline & dengan menggunakan media Math Thinkers? & $(95,24 \%)$ & $(4,76 \%)$ \\
\hline 10. & $\begin{array}{l}\text { Apakah dengan menggunakan media Math } \\
\text { thinkers kamu lebih banyak merespon guru saat } \\
\text { memberi pertanyaan? }\end{array}$ & $\begin{array}{c}15 \\
(71,43 \%)\end{array}$ & $\begin{array}{c}6 \\
(28,57 \%)\end{array}$ \\
\hline
\end{tabular}

Berdasarkan hasil angket yang terdapat dalam Tabel 10 data respon siswa setelah pembelajaran dengan menggunakan media Math Thinkers adalah positif.

Untuk mengetahui efektivitas pembelajaran matematika dengan media Math Thinkers pada siswa kelas VII-B SMP Muhammadiyah 13 Surabaya ada empat aspek yang diteliti, antara lain ketuntasan hasil belajar siswa, aktivitas siswa, kemampuan guru dalam mengelola pembelajaran dan respon siswa.

1. Ketuntasan hasil belajar siswa

Dalam penelitian ini, diberikan tes kepada 21 siswa. Tes dilaksanakan setelah siswa memperoleh pembelajaran matematika dengan media Math Thinkers. Tes ini diawasi oleh guru mata pelajaran dan peneliti untuk mencegah terhadinya kecurangan. Tes dilaksanakan pada tanggal 4 April 2017 pada pukul 13.00-14.30. Tes berlangsung dengan tertib dan tidak ditemukan kecurangan.

Pada Tabel 4 data tes hasil belajar setelah mengikuti pembelajaran dengan media Math Thinkers pada sub kompetensi dasar 1 menunjukkan bahwa 15 siswa atau $71.43 \%$ dari seluruh siswa telah mencapai KKM atau ketuntasan secara individu ( $K K M \geq 75)$, sedangkan siswa yang tidak mencapai $\mathrm{KKM}$ atau ketuntasan secara individu sebanyak 6 siswa atau 28.57\%. Pada tabel 5 data tes hasil belajar setelah mengikuti pembelajaran dengan media Math Thinkers pada sub kompetensi dasar 2 menunjukkan bahwa 15 siswa atau $71.43 \%$ dari seluruh siswa telah mencapai $\mathrm{KKM}$ atau ketuntasan secara individu (KKM $\geq 75)$, sedangkan siswa yang tidak mencapai KKM atau ketuntasan secara individu sebanyak 6 siswa atau $28.57 \%$.

Dengan demikian ketuntasan hasil belajar siswa selama pembelajaran matematika dengan media Math Thinkers secara klasikal tercapai karena jumlah yang tuntas hasil belajarnya $\geq 70 \%$ dari jumlah siswa. Hal ini menunjukkan media Math Thinkers dapat membantu siswa dalam mencapai nilai yang memuaskan. 


\section{Zharotul Azizah}

2. Aktivitas siswa selama mengikuti pembelajaran

Aktivitas siswa diperolah berdasarkan hasil pengamatan yang dicatat selama 5 menit sekali dalam tiap pertemuan pada pembelajaran dengan menggunakan media Math thinkers. Hasil pengamatan aktivitas siswa diperoleh dari lembar observasi aktivitas siswa yang diisi oleh 4 pengamat. Setiap pengamat mengamati setiap 1 kelompok.

Adapun hasil aktivitas siswa pada sub kompetensi dasar 1 ditunjukkan pada Tabel 6, yang menunjukkan setiap aktivitas siswa berada dalam rentang waktu ideal yang telah ditentukan. Hasil aktivitas siswa pada sub kompetensi dasar 2 ditunjukkan pada Tabel 7, menunjukkan bahwa aktivitas siswa nomor 1,2,3,4,5, dan 6 berada dalam rentang waktu ideal yang telah ditentukan.

Jadi aktivitas siswa selama pembelajaran matematika dengan media Math Thinkers adalah efektif. Meskipun masih ada kegiatan yang belum mencapai waktu ideal, namun Math Thinkers dapat membantu siswa agar tertarik selama proses pembelajaran. Banyak siswa yang fokus mencoba menggunakan Math Thinkers selama proses belajar dan siswa menjadi aktif selama proses belajar.

3. Kemampuan guru dalam mengelola pembelajaran

Kemampuan guru dalam mengelola pembelajaran diperoleh dari lembar observasi kemampuan guru dalam mengelola pembelajaran selama pembelajaran matematika dengan menggunakan media Math Thinkers. Lembar observasi kemampuan guru dalam mengelola pembelajaran diisi oleh 1 pengamat tiap pertemuan.

Kemampuan guru dalam mengelola pembelajaran pada sub kompetensi dasar 1 ditunjukkkan pada Tabel 8, yang dihitung dengan tiap rata-rata dari semua pertemuan. Dari seluruh kegiatan untuk tiap tahap pembelajaran dari pertemuan pertama didapatkan rata-rata keseluruhan 3,16. Kemampuan guru dalam mengelola pembelajaran pada sub kompetensi dasar 2 ditunjukkan pada Tabel 9 yang dihitung dengan tiap rata-rata dari semua pertemuan. Dari seluruh kegiatan untuk tiap tahap pertemuan dari pertemuan kedua didapatkan rata-rata keseluruhan 3,1.

Jadi dapat disimpulkan bahwa kemampuan guru dalam mengelola pembelajaran dengan media Math Thinkers dengan langkah-langkah pembelajaran 
yang ada pada RPP selama dua kali pertemuan dilaksanakan dengan baik dan dikatakan efektif. Hal ini menunjukkan bahwa media Math Thinkers membantu guru selama proses pembelajaran, guru menjadi lebih mudah mengajarkan materi sambil melihat gambar, guru juga tidak banyak menjelaskan karena siswa berdiskusi dengan teman sekelompok mereka.

4. Respon siswa terhadap pembelajaran

Hasil respon siswa diperoleh dari angket respon yang diberikan kepada 21 siswa. Angket diberikan setelah siswa mengikuti pembelajaran dengan menggunakan Math Thinkers dan sebelum siswa melakukan tes hasil belajar. Angket respon siswa terdiri dari 10 pertanyaan dengan 2 opsi, yakni "ya" dan "tidak".

Dari Tabel 10 dapat dilihat bahwa pada perolehan skor angket yang diberikan kepada masing-masing siswa paling besar adalah $100 \%$ siswa beranggapan positif terhadap media Math Thinkers untuk pertanyaan 1,2 dan 3 . Dan presentase terendah adalah 71,43\% beranggapan positif terhadap media Math Thinkers untuk pertanyaan 7 dan 10. Sehingga respon siswa terhadap pembelajaran dengan media Math Thinkers untuk seluruh pertanyaan $\geq 70 \%$ atau dalam kategori positif dan dapat dikatakan efektif.

Hal ini menunjukkan siswa senang selama pembelajaran dengan menggunakan media Math Thinkers, terbukti dengan banyaknya respon positif yang diberikan oleh siswa terhadap media Math Thinkers.

\section{SIMPULAN}

Berdasarkan hasil penelitian dan pembahasan yang telah dikemukakan, maka dapat disimpulkan bahwa pembelajaran matematika dengan media Math Thinkers pada siswa kelas VII-B SMP Muhammadiyah 13 adalah efektif, yaitu:

1. Hasil tes belajar setelah mengikuti pembelajaran matematika dengan media Math Thinkers menunjukkan bahwa $\geq 70 \%$ dari seluruh siswa telah mencapai KKM atau ketuntasan secara individu, dengan demikian ketuntasan hasil belajar siswa secara klasikal tercapai. Sehingga dapat disimpulkan ketuntasan hasil belajar siswa setelah mengikuti pembelajaran matematika dengan media Math Thinkers dikatakan efektif. 
2. Aktivitas siswa selama proses pembelajaran matematika dengan media Math Thinkers menunjukkan bahwa hampir semua indikator aktivitas siswa dalam rentang waktu ideal. Dapat disimpulkan bahwa pembelajaran matematika dengan media Math Thinkers dikatakan efektif.

3. Seluruh aktifitas guru yang dilakukan untuk mengetahui kemampuan guru dalam mengelola pembelajaran dari pertemuan pertama hingga ke dua didapatkan rata-rata keseluruhan 3,17 dengan kategori baik dan disimpulkan bahwa kemampuan guru dalam mengelola pembelajaran matematika dengan media Math Thinkers sesuai dengan langkah-langkah pembelajaran yang ada pada RPP selama 2 kali pertemuan. Jadi dapat dikatakan efektif.

4. Hasil analisis respon siswa dapat diperoleh untuk seluruh pertanyaan $\geq 70 \%$ siswa memberikan respon positif terhadap pembelajaran matematika dengan media Math Thinkers dan dapat dikatakan respon siswa pembelajaran matematika dengan media Math Thinkers efektif.

\section{DAFTAR PUSTAKA}

Amala, D. N. (2016). Efektifitas Pembelajaran Matematika Melalui Pendekatan Generative Learning dengan Metode The Study Group pada Siswa Kelas VIII-A di SMP Muhammadiyah 10 Surabaya. Universitas Muhammadiyah Surabaya.

Ariani, W. (2014). Efektifitas Pembelajaran Matematika dengan Model Pembelajaran Reciprocal Teaching pada Siswa Kelas VII di SMP Muhammadiyah 10 Surabya. Universitas Muhammadiya Surabaya.

Nopriana, T. (2017). Berpikir Geometri Melalui Model Pembelajaran Geometri Van Hiele. Delta: Jurnal Ilmiah Pendidikan Matematika, 2(1), 41-50.

Soeparno. (1988). Media Pengajaran Bahasa. Yogyakarta: PT Intan Pariwara.

Trianto. (2009). Mendesain Model Pembelajaran Inovatif-Progresif: Konsep, Landasan, dan Implementasinya pada Kurikulum Tingkat Satuan Pendidikan (KTSP). Jakarta: Kencana Prenada Media Group.

Van de Walle, J. A. (2001). Geometric Thinking and Geometric Concepts. In Elementary and Middle School. Mathematics: Teaching Developmentally, 4th Edition. Boston: Allyn and Bacon. 